ORIGINAL ARTICLE

\title{
Follicular unit transplantation for the treatment of secondary cicatricial alopecia
}

\author{
Huawei Shao $M D^{1}$, Hu Hang $M D P h D^{1}$, Jin Yunyun $M D^{1}$, Jiang Hongfei $M D^{1}$, Han Chunmao $M D P h D^{1}$, \\ Jufang Zhang $M D^{2}$, Haiyan Shen $\mathrm{MD}^{2}$, Fei Zhu $\mathrm{MD}^{2}$, Ming Jia $\mathrm{MD}^{2}$, Yuyan Wang $\mathrm{MD}^{2}$, Xiaobo Guo $\mathrm{MD}^{2}$
}

H Shao, H Hang, J Yunyun, et al. Follicular unit transplantation for the treatment of secondary cicatricial alopecia. Plast Surg 2014;22(4):249-253.

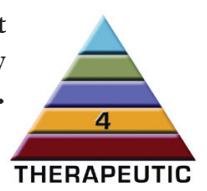

BACKGROUND: Cicatricial alopecia encompasses a diverse group of disorders characterized by the permanent destruction of hair follicles and irreversible hair loss. Follicular unit transplantation was developed in 1994. However, large-scale clinical trials are necessary to study follicular unit transplantation for treating Chinese cicatricial alopecia patients.

OBJECTIVE: To investigate the efficacy of follicular unit transplantation in the treatment of cicatricial alopecia in Chinese patients.

METHODS: Patients with cicatricial alopecia were enrolled. The designated recipient area, follicular unit density of the donor site, transplanted density and operative time were recorded. Postoperative follow-up was conducted within six to 24 months; the density of hair in the recipient area was calculated using a Folliscope (Hansderma Co, USA). Patients' selfreported satisfaction and long-term complications were recorded.

RESULTS: Thirty-seven patients were enrolled. Cicatricial alopecia was caused by burns $(n=8)$, trauma $(n=21)$ and plastic surgery (cleft lip and palate repair $[n=8])$. Burn patients had a significantly larger bald area than the other patients $(\mathrm{P}<0.01)$. The operative time was significantly correlated with recipient area. The longest operation was $14.5 \mathrm{~h}$; the largest transplanted area was $96 \mathrm{~cm}^{2}$. At follow-up, the surviving follicular unit density/transplanted follicular unit density rate was $64.29 \%$ to $95.00 \%$ (mean $78.96 \%$ ); the surviving/transplanted (S/T) area was $100 \%$ for 30 patients, $90 \%$ to $100 \%$ for five patients and $<90 \%$ for two patients. The lowest $\mathrm{S} / \mathrm{T}$ area was $82.81 \%$. The $\mathrm{S} / \mathrm{T}$ index was significantly and inversely correlated with operative time. Regarding long-term complications, two patients had postoperative epidermoid cysts that healed with local treatment.

CONCLUSION: Follicular unit transplantation is an effective method for treating cicatricial alopecia. It is relatively safe and yields satisfactory postoperative results. Extending the results of the present study to Chinese clinical practice is warranted.

Key Words: Cicatricial alopecia; Follicular unit transplantation (FUT); Hair transplantation

$\mathrm{H}^{2}$ aving hair on the scalp is a human characteristic that conveys aspects of self-image, identity and health. Hair loss may result in disturbed self-perception and psychological conflict. Cicatricial alopecia encompasses a diverse group of disorders characterized by the permanent destruction of hair follicles and irreversible hair loss.

Alopecia is typically divided into cicatricial and noncicatricial (nonscarring) forms. Cicatricial alopecia describes follicular epithelium that has been replaced by connective tissue and is, therefore, an irreversible process. However, nonscarring alopecia is potentially reversible because the follicular epithelia remain intact (1). In secondary cicatricial alopecia, the follicle is an 'innocent bystander' and is not specifically destroyed. Destruction of hair follicles may be secondary to an inflammatory process such as kerion, trauma or radiation

\section{La greffe folliculaire pour le traitement de l'alopécie cicatricielle secondaire}

HISTORIQUE : L'alopécie cicatricielle englobe un groupe diversifié de
troubles caractérisés par la destruction permanente de follicules pileux et
une perte de cheveux irréversible. La greffe folliculaire a été mise au
point en 1994. Cependant, des essais cliniques à grande échelle
s'imposent pour l'étudier dans le traitement de l'alopécie cicatricielle
chez des patients chinois. OBJECTIF : Étudier l'efficacité de la greffe folliculaire pour traiter l'alopécie cicatricielle chez des patients chinois.

MÉTHODOLOGIE : Les chercheurs ont recruté des patients présentant une alopécie cicatricielle. Ils ont consigné la zone désignée, la densité des unités folliculaires au foyer du donneur, la densité greffée et le temps d'opération. Ils ont effectué un suivi postopératoire dans les six à 24 mois et calculé la densité pileuse du receveur à l'aide d'un folliscope (Hansderma Co, États-Unis). Ils ont consigné la satisfaction des patients et les complications à long terme.

RÉSULTATS : Trente-sept patients ont participé. L'alopécie cicatricielle était causée par des brûlures $(n=8)$, des traumatismes $(n=21)$ et la chirurgie plastique (réparation d'une fissure palatine et labiale $[n=8]$ ). Les patients brûlés présentaient des zones d'alopécie beaucoup plus importantes que les autres patients $(\mathrm{P}<0,01)$. Le temps de l'opération était corrélé avec la zone du receveur. L'opération la plus longue a pris 14,5 heures et la greffe la plus vaste était de $96 \mathrm{~cm}^{2}$. Au suivi, le ratio entre la densité des unités folliculaires survivantes et la densité des unités folliculaires greffées variait entre 64,29 \% et 95,00 \% (moyenne de 78,96\%). Le ratio entre la zone survivante et la zone greffée (S/T) était de $100 \%$ pour 30 patients, de $90 \%$ à $100 \%$ pour cinq patients et de moins de $90 \%$ pour deux patients. La zone S/T la plus faible était de 82,81\%. L'indice S/T, significatif, était inversement proportionnel avec la durée de l'opération. Pour ce qui est des complications à long terme, deux patients ont présenté des kystes épidermoïdes postopératoires qui ont guéri grâce à un traitement localisé.

CONCLUSION : La greffe folliculaire traite l'alopécie cicatricielle avec efficacité. Relativement sécuritaire, elle donne des résultats postopératoires satisfaisants. Il faudra étendre les résultats de la présente étude à la pratique clinique en Chine.

therapy, or can be caused by a carcinoma or a metastatic tumour (2). Reconstructive treatments for the face and scalp after such destruction are important for the physical and physiological well-being of the patient (3).

Traditional surgical treatments for secondary cicatricial alopecia include excision, scar reduction, tissue expansion and scalp flap. However, these procedures often result in unfavourable scarring or hair growth direction. In 1959, Orentreich (4) described the phenomenon of donor dominance in androgenic alopecia, thus paving the way for hair transplantation. For many years, the standard of care was to place a $4 \mathrm{~mm}$ plug into a $3 \mathrm{~mm}$ hole. Each $4 \mathrm{~mm}$ punch graft comprised 15 to 20 hairs, the resulting tuft growth was known as 'doll's hair'. In 1994, Limmer (5) described the use of a stereomicroscope for

${ }^{1}$ Department of Burns and Wound Center, Second Affiliated Hospital, College of Medicine, Zhejiang University; ${ }^{2}$ Department of Plastic Surgery,

Hangzhou First People's Hospital, Hangzhou, People's Republic of China

Correspondence: Dr Jufang Zhang, Department of Plastic Surgery, Hangzhou First People's Hospital, 261\# HuanSha Road, Hangzhou,

Zhejiang Province, Hangzhou 310006, People's Republic of China. Telephone 0086-571-56006533, fax 0086-571-87060047,

e-mail huhangbob@aliyun.com 


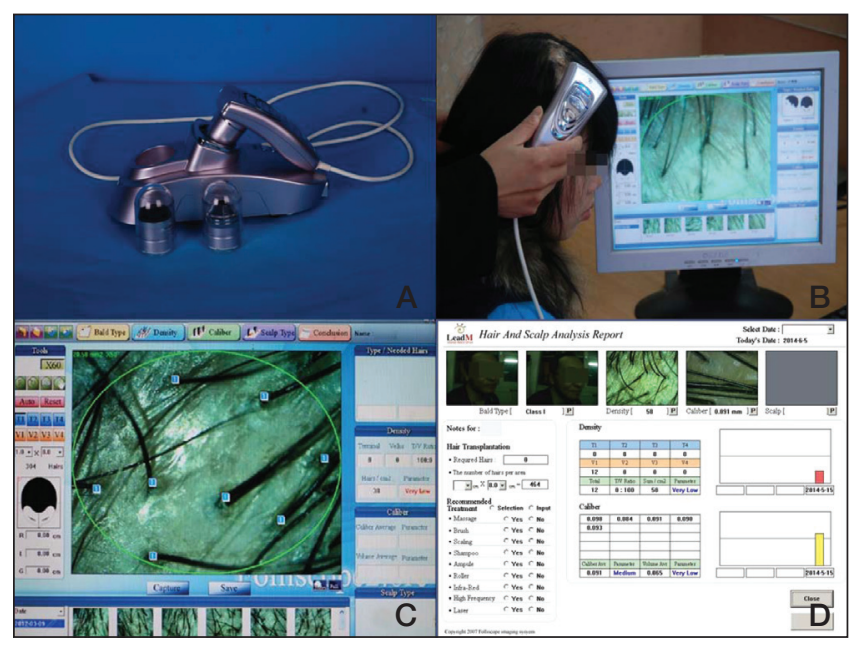

Figure 1) Calculating the follicular unit (FU) density using a Folliscope (Hansderma Co, USA) FU density detector. A Folliscope FU density detector. B Sampling a patient's FU density. C Automatic calculation of FU density. D Reporting the generated output

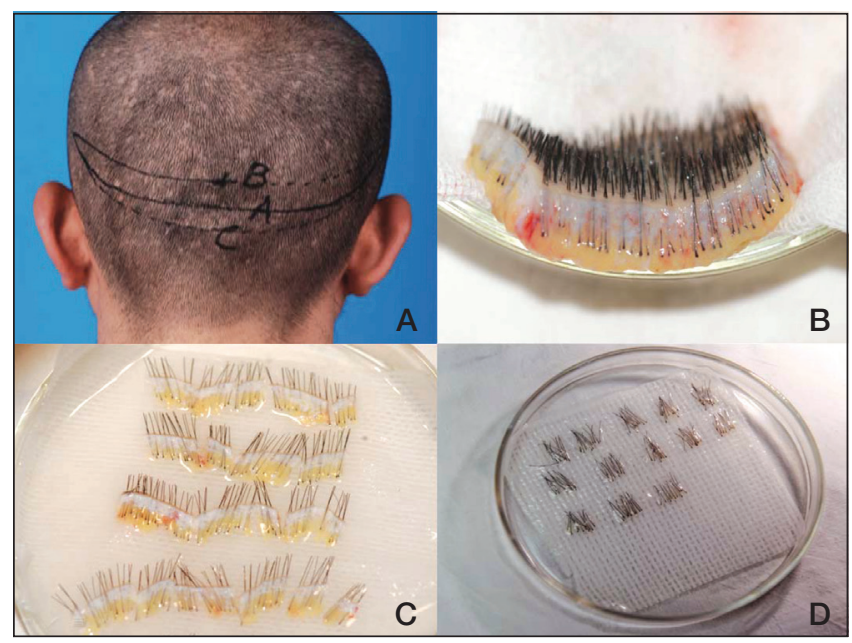

Figure 2) Follicular unit transplantation harvest and preparation procedures. A Marked donor strip. B Excised donor strip. C Donor strip divided crosswise into slivers containing one to two rows of follicular units. D Further dissection of the follicular units placed on gauze in saline at $4^{\circ} \mathrm{C}$

the dissection of a donor strip. They did not dissect the grafts based on size, but rather on follicle groupings that usually contained one, two or three hairs. The application of follicular units (FUs) enabled the technique to be minimally invasive with genrally acceptable aesthetic results $(4,6,7)$.

However, the effect of FU transplantation (FUT) in the treatment of Chinese cicatricial alopecia patients necessitates validation in large-scale clinical trials. In the current report, we present our experience with treating secondary cicatricial alopecia using FUT.

\section{METHODS}

Patients and criteria

From January 2005 to December 2010, 37 patients with cicatricial alopecia were consecutively admitted for treatment. The exclusion criteria included subjects who refused FUT therapy, as well as subjects with alopecia areata or other nonscarring alopecia conditions. The Institutional Review Board of Hangzhou First People's Hospital (Hangzhou, China) approved the present study.

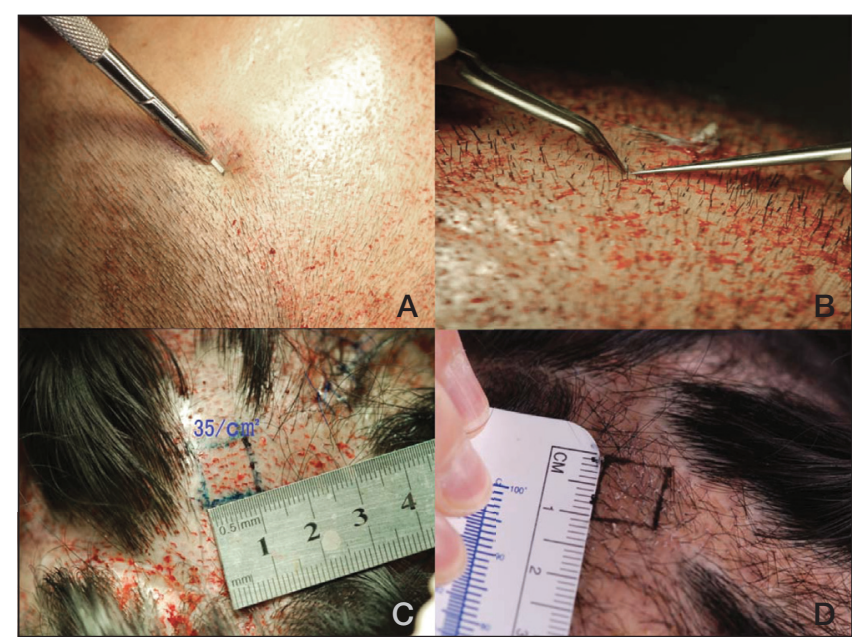

Figure 3) Follicular unit transplantation and follow-up procedures. A Incisions were created with rectangular, chisel-shaped blades. B The follicular units were transplanted using microsurgical forceps. C The density of the follicular units was 35 units $/ \mathrm{cm}^{2}$. D Hair density at a follow-up visit

\section{Information collection}

Basic characteristics, including medical history, general physical examination and laboratory results, were recorded. Operation-related indexes, including the density of FUs on the patient's scalp (units $/ \mathrm{cm}^{2}$ ) and bald area $\left(\mathrm{cm}^{2}\right)$, were calculated and recorded. The density of FUs was calculated using a Folliscope (Hansderma Co, USA) FU density detector (Figure 1). The patient's bald area was traced onto transparent paper. Area measurements $\left(\mathrm{cm}^{2}\right)$ were subsequently performed using millimetre paper.

\section{Surgical planning and harvest procedures}

FUT was conducted after obtaining informed written consent. All operations were performed under local anesthesia on an outpatient basis. The scalp was prepared by cutting the patient's hair to a length of approximately $2 \mathrm{~mm}$ to $3 \mathrm{~mm}$ and by washing the hair on the day of the operation. The operative technique involved four steps: extraction of the donor strip; microscopic dissection of the donor strip into FUs; creation of recipient incisions; and implantation of follicular grafts (Figures 2 and 3).

For all operations, the occipital zone of the scalp was chosen as the donor site. The donor strip sizes were calculated based on the previously described bald area and the density of the FUs on the patient's donor scalp (units $/ \mathrm{cm}^{2}$ ). The excision area was disinfected with $2 \%$ chlorhexidine lotion and marked according to the required size of the donor strip (Figure 2A). An occipital nerve block using $4 \mathrm{~mL}$ of $2 \%$ lidocaine $(80 \mathrm{mg}$ ) was first administered to the occipital donor scalp area. Subsequently, a mixture of $100 \mathrm{~mL}$ of $0.9 \%$ sodium chloride, $10 \mathrm{~mL}$ of $2 \%$ lidocaine $(200 \mathrm{mg})$ and $0.5 \mathrm{mg}$ of epinephrine $(1: 100,000)$ was infiltrated into the subcutaneous region of the donor areas to achieve local anesthesia. The patients remained awake during the surgery and reported the anesthetic effect. For several anxious patients or those with hyperalgesia and allodynia, an anesthesiologist administered intravenous sedation that was maintained during the invasive surgical procedures.

The designed donor strip was excised from the occipital region with the patient lying prone. The incision was made parallel to the line of hair follicles at a depth of $5 \mathrm{~mm}$ to $7 \mathrm{~mm}$ to reach the deep subcutaneous tissue slightly below the hair bulbs (Figure 2B). The donor area was then closed with a simple running stitch using 4-0 monofilament sutures while taking close bites that were less than the hair follicle depth to minimize damage to the hair bulbs.

The excised donor strip was then dissected using a stereomicroscope to obtain the FUs for implantation in the recipient area. The donor strip was divided crosswise into slivers, each containing one to 
TABLE 1

\section{Basic characteristics}

\begin{tabular}{ll}
\hline Characteristic & \\
\hline Male sex, $\mathrm{n}(\%)$ & $37(20)$ \\
Age, years & $24.68 \pm 5.88$ \\
Cause (burn/trauma/surgery), $\mathrm{n} / \mathrm{n} / \mathrm{n}$ & $8 / 21 / 8$ \\
Bald region (hair/eyebrow/beard), $\mathrm{n} / \mathrm{n} / \mathrm{n}$ & $24 / 7 / 6$ \\
Duration, years & $6.24 \pm 6.89$ \\
Area of bald region, $\mathrm{cm}^{2}$ & $16.27 \pm 31.74$ \\
Donor FU density, $\mathrm{FU} / \mathrm{cm}^{2}$ & $91.41 \pm 3.14$ \\
\hline
\end{tabular}

Data presented as mean \pm SD unless otherwise indicated. FU Follicular unit

two rows of FUs (Figure 2C). The fragments were then further dissected under magnification into units containing clusters of one, two or three follicles. The dermal tissue around the follicles was trimmed away. The donor strip and separated FUs were placed on gauze infiltrated with saline at $4^{\circ} \mathrm{C}$ (Figure 2D). All procedures, including dissection, separation and calculation, were performed under cool, wet conditions, which was important for the maintenance of graft viability. On average, the authors generally used four to six dissectors.

\section{FUT procedures}

The recipient area was disinfected with $2 \%$ chlorhexidine lotion, and supraorbital and trochlear nerve blocks using $2 \mathrm{~mL}$ of $2 \%$ lidocaine $(40 \mathrm{mg})$ were administered to the forehead recipient area. The recipient area was then distended using a mixture of $100 \mathrm{~mL}$ of $0.9 \%$ sodium chloride, $10 \mathrm{~mL}$ of $2 \%$ lidocaine $(200 \mathrm{mg})$ and $0.5 \mathrm{mg}$ of epinephrine (1:100000). This distension widened and stretched the surface area, thus facilitating slit opening. Incisions were unsystematically created using rectangular chisel-shaped blades (width $0.9 \mathrm{~mm}$ to $1.1 \mathrm{~mm}$ ) to a $4.5 \mathrm{~mm}$ depth in an anterior-posterior direction, following the direction of natural hair growth on the scalp (Figure 3A).

The graft was transplanted using microsurgical forceps under highquality loupe magnification (Figure 3B). Exerting any pressure on the root of the follicle was carefully avoided during transplantation. The density of the FUs was 15 to 40 units $/ \mathrm{cm}^{2}$ (Figure 3C). The total number of transplanted FUs was 1000 units to 3300 units, depending on the area of the bald zone. Once all grafts had been inserted, the donor area was protected with a dressing held in place by a headband.

The scalp was carefully cleaned and checked the next day. If any grafts were extruding, they were replaced with one to two FU grafts that had been set aside overnight in sterile, refrigerated saline.

\section{Follow-up}

A follow-up visit was scheduled 12 months after surgery (Figure 3D). The density of hair in the recipient area was calculated using a Folliscope (as previously described), and long-term complications (if any) and the patients' self-reported satisfaction were recorded.

\section{Data collection and statistical analysis}

Continuous variables are expressed as mean \pm SD and enumeration data are expressed as a percentage; $\mathrm{P}<0.05$ was considered to be statistically significant. A statistical analysis was performed using SPSS version 11.5 (IBM Corporation, USA) for Windows (Microsoft Corporation, USA). A multivariate linear correlation was conducted to interpret the effect of other factors on the final follow-up result (surviving FU density/transplanted FU density rate and the surviving/ transplanted area $[S / T]$ index]).

\section{RESULTS}

\section{Basic characteristics}

Thirty-seven patients ( 20 male, 17 female) were enrolled for FUT. The patients ranged in age from 12 to 42 years (mean age 24.68 years). Cause for baldness included burn $(n=8)$, trauma $(n=21)$ and plastic surgery (cleft lip and palate repair) $(n=8)$. Basic characteristics of the patients are summarized in Table 1.
TABLE 2

\section{Surgical information}

\begin{tabular}{ll}
\hline Cohort & \\
\hline Recipient area, $\mathrm{cm}^{2}$ & $10.08 \pm 19.55$ \\
Recipient area/bald area, \% & $93.42 \pm 21.4$ \\
Recipient FU density, FU/cm ${ }^{2}$ & $36.28 \pm 6.44$ \\
Operative time, $\mathrm{h}$ & $3.61 \pm 1.32$ \\
\hline
\end{tabular}

Data presented as mean \pm SD. FU Follicular unit

\section{TABLE 3}

\section{Follow-up data}

\begin{tabular}{ll}
\hline Cohort & \\
\hline Postoperative follow-up, months & $13.89 \pm 6.13$ \\
Surviving recipient area, $\mathrm{cm}^{2}$ & $9.55 \pm 18.01$ \\
Surviving/transplanted area, \% & $98.30 \pm 4.24$ \\
Surviving FU density, FU/cm ${ }^{2}$ & $28.70 \pm 5.56$ \\
Surviving/transplanted FU density, \% & $78.96 \pm 6.43$ \\
Long-term complications & Epidermoid cysts $(\mathrm{n}=2)$ \\
\hline
\end{tabular}

Data presented as mean \pm SD. FU Follicular unit

The duration of baldness for the patients who had undergone a cleft lip and palate repair was significantly longer than that of the other patients $(\mathrm{P}<0.01)$. For the burn patients, the bald area was significantly larger than that of the other patients $(\mathrm{P}<0.01)$. There was no significant difference in the three causes among the indexes including donor FU density and patient age $(\mathrm{P}>0.05)$.

\section{Surgical information}

FUT-related information is summarized in Table 2.

The bivariate linear correlation result indicated that operative time was significantly correlated with recipient area (Pearson's $\mathrm{P}<0.01)$. The longest transplant operation was $7.5 \mathrm{~h}$. Full coverage (recipient area/bald area $=100 \%)$ was achieved for each of the 32 patients who had a bald area $\leq 30 \mathrm{~cm}^{2}$. For the five other patients who had a bald area $>30 \mathrm{~cm}^{2}$, full coverage was achieved for only one $\left(96 \mathrm{~cm}^{2}\right)$. This patient also had the largest transplanted area and second longest transplantation time $(7 \mathrm{~h})$ in the present study.

\section{Follow-up information}

The follow-up visits were anticipated to occur 12 months after FUT; however, the actual follow-up visits were performed six to 24 months postoperatively due to poor patient compliance. The density of hair in the recipient area was calculated using a Folliscope. The patients' self-reported satisfaction and long-term complications (if any) were also recorded. Information related to the follow-up visits is listed in Table 3.

At the follow-up visit, the surviving FU density/transplanted FU density rate was $64.29 \%$ to $95.00 \%$, with a mean value of $78.96 \%$. The surviving/transplanted area (S/T index) was $100 \%$ for 30 patients, $90 \%$ to $100 \%$ for five patients and $<90 \%$ for two patients; the lowest S/T index was $82.81 \%$. The multivariate linear correlation result indicated that the $\mathrm{S} / \mathrm{T}$ index was significantly and inversely correlated with operative time and had no correlation with any other parameter; however, the surviving FU density/transplanted FU density rate had no correlation with any other parameter. Regarding long-term complications, two patients had postoperative epidermoid cysts that healed with local treatment.

\section{DISCUSSION}

Cicatricial alopecia secondary to burns, trauma, surgery or radiotherapy is a distressing problem. The surgical restoration of hair loss has witnessed some improvements over the past decade, including the use of punch grafts, surgical excision (alopecia reduction), tissue expansion, scalp flaps and free autografts of hair-bearing scalp to resurface alopecia $(8,9)$. However, these procedures often result in unfavourable scarring or hair growth direction. 
Over the past two decades, attempts to achieve more aesthetically pleasing results have led to developments such as minigrafts, micrografts and FUT. The term 'follicular unit' was first defined by Headington (10) as a naturally occurring group of one to four terminal hairs that are present on the scalp. Each of these units contains sebaceous glands, a neurovascular plexus, an arrector pili muscle and a few vellus hairs. The principle relies on harvesting a donor strip from the occipital region of the scalp that is genetically not programmed for hair loss (even in the baldest individual), dissecting the donor strip into grafts and transplanting these dissected grafts into the areas of aesthetic importance.

For the FUT technique, FUs can be prepared more easily under magnification, enabling a denser graft placement in the recipient area and, thus, providing a more natural appearance. The technique has become widely accepted, and up to 61 hairs $/ \mathrm{cm}^{2}$ have been transplantted during a single procedure. FUT creates fewer disturbances in the patient's life, with minimal surgical risk and no disfigurement, and has become one of the most versatile techniques available for hair restoration.

Although hair transplantation is a good option for cicatricial alopecia, it is a challenge for surgeons because of tissue stiffness and poor blood circulation, as well as the frequently required changes in the direction of hair growth. Furthermore, some important factors, such as dehydration, physical trauma, hair density in the transplanted area and hair growth direction, may affect the final result. If the grafts are not continuously well hydrated in a physiological saline solution from extraction to implantation they may dry out, causing a reduction in survival rate (11). Physical damage may be caused by desiccation, forceps pressure or scalpel slip, and can cause damage to the follicular bulb and have a negative impact on hair growth.

Density in the transplanted area is affected by two factors: the calibre of the transplanted hair and the number of FUs implanted $/ \mathrm{cm}^{2}$ of recipient area. The density of incisions in the recipient area is one of the most difficult decisions for a surgeon who is operating in a region of cicatricial alopecia. A relatively higher-density FUT is essential for a better appearance. However, the blood supply in scars is limited and may lead to poor graft survival. Densities generally vary from $15 \mathrm{FU} / \mathrm{cm}^{2}$ to $20 \mathrm{FU} / \mathrm{cm}^{2}$. In our study, we chose an FU density of $20 \mathrm{FU} / \mathrm{cm}^{2}$ to $48 \mathrm{FU} / \mathrm{cm}^{2}$, with a mean value of $36.28 \mathrm{FU} / \mathrm{cm}^{2}$. Our result indicated that this density is sufficient for the patients' postoperative appearance and had an acceptable FU survival rate during long-term follow-up. In general, even higher FU densities are not recommended in areas of cicatricial alopecia.

However, there were some limitations in our FUT investigation. First, only 37 patients were enrolled, two-fifths of whom underwent FUT for cicatricial alopecia in their eyebrow and beard regions. Patients with a large area of scarring alopecia of the scalp (especially post-trauma) were relatively few, and only five patients had a transplanted area $>60 \mathrm{~cm}^{2}$. However, this ratio reflected the normal proportion of patients who received such therapy in our centre.

Second, this technique requires a longer operative time (our longest operation was $14.5 \mathrm{~h}$ ), which was a significant challenge for both the surgeon and patient. Moreover, the survival of the transplanted grafts may have been affected by the time that the grafts remained in saline before transplantation.

Third, the investigation was designed to have a follow-up visit 12 months after the FUT; however, the actual follow-up was performed six to 24 months postoperatively due to poor patient compliance. This significant difference in follow-up may have affected the consistency of our results; however, the multivariate linear correlation analysis indicated that the surviving FU density/transplanted FU density rate had no correlation with any other parameter including follow-up duration.

Finally, using a donor source of only head-derived hair may not adequately serve the needs of severe cicatricial alopecia patients. Because the average safe donor area contains approximately 12,500 movable hairs (12) and the average head graft consists mostly of two to three hairs per follicle, this would translate into no more than 6000 follicles. Thus, for patients with a large bald area, FUT cannot achieve full coverage. Recently, Umar (13) reported the application of a large number (>8000 grafts) of nonhead hairs (mainly body and beard sources) in hair transplantation. This may expand donor sources and provide new possibilities for severe cicatricial alopecia.

\section{CONCLUSION}

Our investigation demonstrated that FUT is a good method for treating cicatricial alopecia with several advantages including minimal invasiveness, relatively safety, high transplantation density and satisfactory postoperative results. Extending our experience to Chinese clinical practice is warranted.

\section{SUPPLEMENTAL TYPICAL CASES}

Case 1

The patient was a 19-year-old woman with a $95 \mathrm{~cm}^{2}$ bald area on her scalp secondary to a burn injury that occurred 12 years previously (Figure 4A). The FU density of her donor site was $60 \mathrm{FU} / \mathrm{cm}^{2}$. A total of 2375 FUs were transplanted into a $95 \mathrm{~cm}^{2}$ recipient area during surgery. The recipient area/bald area was $100 \%$; the transplanted FU density was $25 \mathrm{FU} / \mathrm{cm}^{2}$; and the duration of the procedure was $14.5 \mathrm{~h}$. Figure $4 \mathrm{~B}$ depicts thriving hair growth in the recipient area at her 24-month follow-up visit. The S/T area was $100 \%$; the surviving FU density was $25 \mathrm{FU} / \mathrm{cm}^{2}$; and the S/T FU density was $80 \%$.

Case 2

The patient was a 21-year-old man with a $100 \mathrm{~cm}^{2}$ bald area on his scalp due to a burn injury that occurred 15 years previously (Figure $5 \mathrm{~A}$ ). His donor site FU density was $75 \mathrm{FU} / \mathrm{cm}^{2}$. A total of $3000 \mathrm{FUs}$ were transplanted into a $100 \mathrm{~cm}^{2}$ recipient area during surgery. The recipient area/ bald area was $100 \%$; the transplanted FU density was $30 \mathrm{FU} / \mathrm{cm}^{2}$; and the duration of the procedure was $14 \mathrm{~h}$. Figure $5 \mathrm{~B}$ depicts thriving hair growth in the recipient area at his 24-month follow-up visit. The S/T area was $97 \%$; the surviving FU density was $22 \mathrm{FU} / \mathrm{cm}^{2}$; and the S/T FU density was $73.3 \%$.

Case 3

The patient was a 15-year-old girl with a $3 \mathrm{~cm}^{2}$ bald area of the left eyebrow after a traumatic injury that occurred five years previously (Figure 6A). The FU density of her donor site was $75 \mathrm{FU} / \mathrm{cm}^{2}$. A total of $150 \mathrm{FUs}$ were transplanted into a $3 \mathrm{~cm}^{2}$ recipient area during surgery. The recipient area/bald area was 100\%; the transplanted FU density was $50 \mathrm{FU} / \mathrm{cm}^{2}$; and the duration of the procedure was $2.5 \mathrm{~h}$. Figure $6 \mathrm{~B}$ depicts thriving eyebrow hairs in the recipient area at her 12 -month follow-up visit. The S/T area was 100\%; the surviving FU density was $45 \mathrm{FU} / \mathrm{cm}^{2}$; and the S/T FU density was $90 \%$.

\section{REFERENCES}

1. Abal-Diaz L, Soria X, Casanova-Seuma JM. [Scarring alopecia]. Actas Dermosifiliogr 2012;103:376-87.

2. Sperling LC, Cowper SE. The histopathology of primary cicatricial alopecia. Semin Cutan Med Surg 2006;25:41-50.

3. Gho CG, Neumann HA. Improved hair restoration method for burns. Burns 2011;37:427-33.

4. Orentreich N. Autografts in alopecias and other selected dermatological conditions. Ann N Y Acad Sci 1959;83:463-79.

5. Limmer BL. Elliptical donor stereoscopically assisted micrografting as an approach to further refinement in hair transplantation. J Dermatol Surg Oncol 1994;20:789-93.

6. Rassman WR, Carson S. Micrografting in extensive quantities. The ideal hair restoration procedure. Dermatol Surg 1995;21:306-11.

7. Bernstein RM, Rassman WR. Follicular transplantation. Patient evaluation and surgical planning. Dermatol Surg 1997;23:771-84.

8. Yang CC. Calvitron automated hair transplant system in alopecia treatment: A case report. Kaohsiung J Med Sci 2003;19:470-5.

9. Shiell RC. Modern hair restoration surgery. Clin Dermatol 2001;19:179-87. 


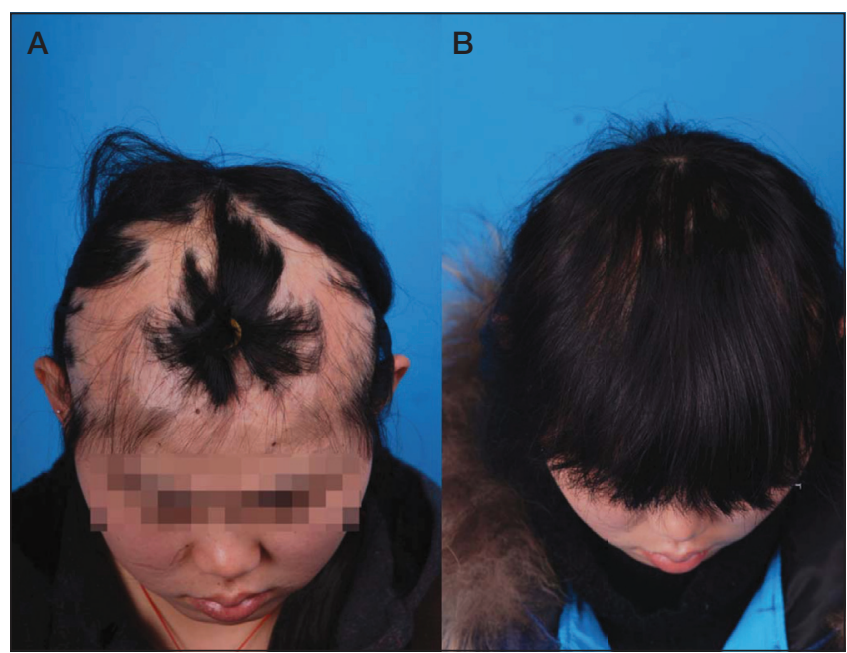

Figure 4) Prefollicular unit transplantation (A) and 24-month follow-up visit (B) photographs of a 19-year-old woman who experienced a burn injury 12 years previously

10. Headington JT. Transverse microscopic anatomy of the human scalp. A basis for a morphometric approach to disorders of the hair follicle. Arch Dermatol 1984;120:449-56.

11. Gandelman M, Mota AL, Abrahamsohn PA, De Oliveira SF. Light and electron microscopic analysis of controlled injury to follicular unit grafts. Dermatol Surg 2000;26:25-30.

12. Bernstein RM, Rassman WR. The logic of follicular unit transplantation. Dermatol Clin 1999;17:277-95,viii; discussion 296.

13. Umar $\mathrm{S}$. Hair transplantation in patients with inadequate head donor supply using nonhead hair: Report of 3 cases. Ann Plast Surg 2011;67:332-5.

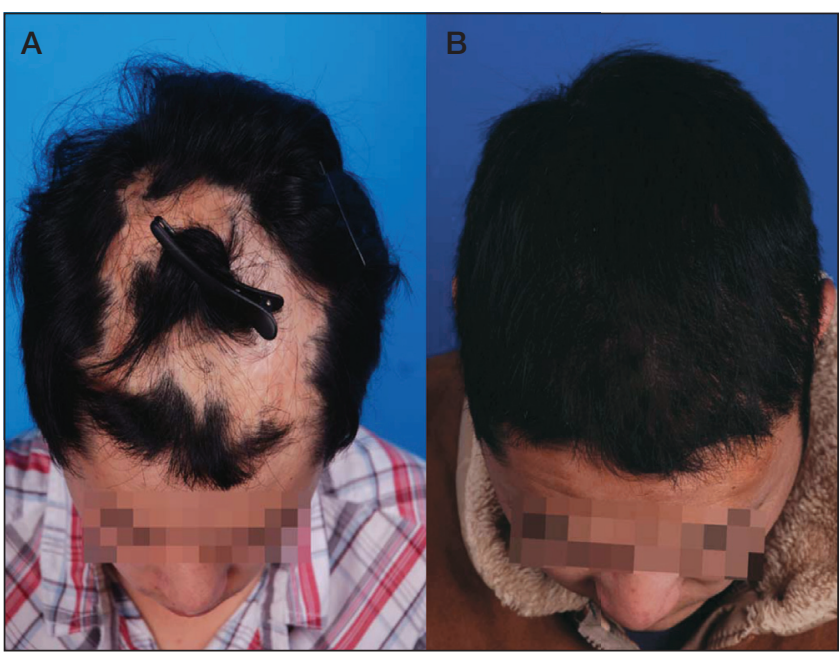

Figure 5) Prefollicular unit transplantation (A) and 24-month follow-up visit (B) photographs of a 21-year-old man who experienced a burn injury 15 years previously

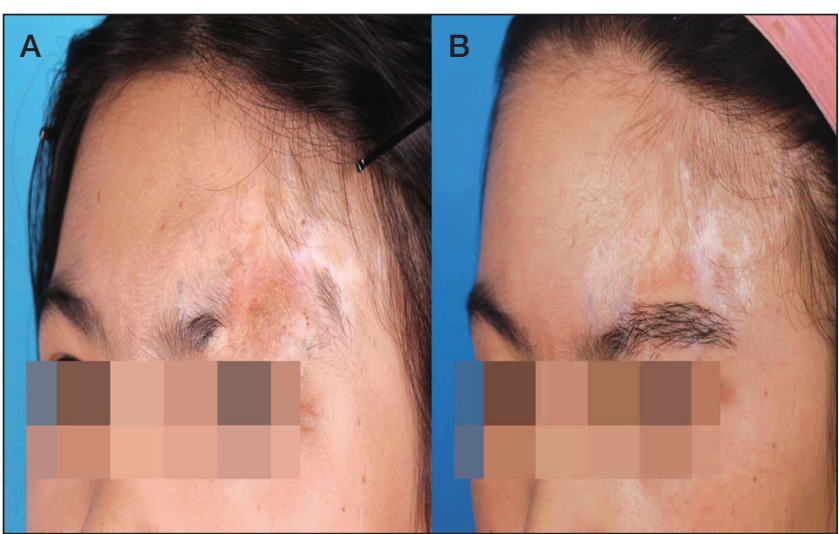

Figure 6) Prefollicular unit transplantation (A) and 24-month follow-up visit (B) photographs of a 15-year-old girl who experienced a traumatic injury five years previously 